\title{
Identification of the Core Structure of Lysozyme Amyloid Fibrils by Proteolysis
}

\section{Erica Frare ${ }^{1}$, Maria F. Mossuto ${ }^{1}$, Patrizia Polverino de Laureto ${ }^{1}$ Mireille Dumoulin $^{2}$, Christopher M. Dobson ${ }^{2}$ and Angelo Fontana ${ }^{1 *}$}

${ }^{1}$ CRIBI Biotechnology Centre University of Padua, Viale G. Colombo 3, 35121 Padua, Italy

${ }^{2}$ Department of Chemistry University of Cambridge Lensfield Road, Cambridge CB2 1EW, UK

\begin{abstract}
Human lysozyme variants form amyloid fibrils in individuals suffering from a familial non-neuropathic systemic amyloidosis. In vitro, wild-type human and hen lysozyme, and the amyloidogenic mutants can be induced to form amyloid fibrils when incubated under appropriate conditions. In this study, fibrils of wild-type human lysozyme formed at low $\mathrm{pH}$ have been analyzed by a combination of limited proteolysis and Fouriertransform infrared (FTIR) spectroscopy, in order to map conformational features of the 130 residue chain of lysozyme when embedded in the amyloid aggregates. After digestion with pepsin at low $\mathrm{pH}$, the lysozyme fibrils were found to be composed primarily of $\mathrm{N}$ and C-terminally truncated protein species encompassing residues $26-123$ and 32-108, although a significant minority of molecules was found to be completely resistant to proteolysis under these conditions. FTIR spectra provide evidence that lysozyme fibrils contain extensive $\beta$-sheet structure and a substantial element of non $\beta$-sheet or random structure that is reduced significantly in the fibrils after digestion. The sequence $32-108$ includes the $\beta$-sheet and helix $C$ of the native protein, previously found to be prone to unfold locally in human lysozyme and its pathogenic variants. Moreover, this core structure of the lysozyme fibrils encompasses the highly aggregation-prone region of the sequence recently identified in hen lysozyme. The present proteolytic data indicate that the region of the lysozyme molecule that unfolds and aggregates most readily corresponds to the most highly protease-resistant and thus highly structured region of the majority of mature amyloid fibrils. Overall, the data show that amyloid formation does not require the participation of the entire lysozyme chain. The majority of amyloid fibrils formed from lysozyme under the conditions used here contain a core structure involving some $50 \%$ of the polypeptide chain that is flanked by proteolytically accessible $\mathrm{N}$ and C-terminal regions.

C) 2006 Elsevier Ltd. All rights reserved.
\end{abstract}

Keywords: lysozyme; amyloid fibrils; FTIR spectroscopy; limited proteolysis; electron microscopy fibrils that are deposited in a variety of organs and tissues. ${ }^{1-5}$ Among the amyloidogenic proteins are the A $\beta$ peptide involved in Alzheimer's disease, the islet amyloid polypeptide involved in type II diabetes, $\alpha$-synuclein involved in Parkinson's disease and the prion proteins in the transmissible spongiform encephalopathies. ${ }^{6}$ Although the proteins associated with amyloid diseases differ in their primary and tertiary structures, as well as their size and function, all of them form elongated amyloid fibrils that are similar to each other in structure and properties. ${ }^{7,8}$ They possess a common cross- $\beta$ structural motif, having $\beta$-strands oriented perpendicular to the fibril axis, and they bind selectively the 
aromatic dyes Congo $\operatorname{Red}^{9}$ and thioflavin T (ThT). ${ }^{10}$ More recently, it has been found that proteins not associated with human disease can be induced to form amyloid fibrils in vitro. On this basis, the ability to form amyloid fibrils has been suggested to be a general property of the polypeptide chain. ${ }^{5,11-13}$

The single-point mutants of lysozyme I56T, F57I, W64R and D67H, ${ }^{14-17}$ and the two double mutants F57I/T70N and W112R/T70N, 16,18 have been found to form amyloid plaques in individuals suffering from non-neuropathic hereditary amyloidosis. Another natural variant, T70N, has been found in $5 \%$ of the British population and $12 \%$ of the Caucasian Canadian population but has not so far been associated with disease. ${ }^{16,19}$ It has been shown that the I56T, F57I, W64R and D67H variants are less stable than the wild-type protein. ${ }^{20-22}$ Despite its greater stability, however, wild-type human lysozyme can form fibrils in vitro that are very similar to those of the pathological variants; for example, when incubated at low $\mathrm{pH}$ and elevated temperature ${ }^{23}$ or following application of high hydrostatic pressure. ${ }^{24}$ Lysozyme is an excellent system with which to study protein aggregation processes, as its structure and folding mechanism are known in great detail. ${ }^{25,26}$ Moreover, the mechanism of aggregation of both variant and wild-type lysozymes has been investigated in depth. ${ }^{27}$ It has been shown that the region encompassing the $\beta$-sheet and helix $C$ of the amyloidogenic variants I56T and D67H undergoes a locally cooperative unfolding event under physiologically relevant conditions. ${ }^{21,28}$ A proteolytic fragment encompassing approximately the same sequence region in the highly homologous hen eggwhite protein has been found to be the most aggregation-prone segment of the protein, at least at acid $\mathrm{pH} .{ }^{29}$ Moreover, synthetic fragments corresponding to the $\beta$-sheet region of hen lysozyme have been shown to form amyloid structures very readily. ${ }^{30}$ Overall, this evidence has led to the hypothesis that lysozyme amyloid fibril formation may be initiated by the partial unfolding of the central region of the protein encompassing the $\beta$ domain and the $C$-helix located in the alpha-domain, to which it is linked by a disulfide bond. ${ }^{20,21}$

While many molecular features of the process of lysozyme aggregation are known from these previous studies, a detailed molecular description of the protein aggregates, including the mature fibrils, is still an important objective. Despite the intrinsic heterogeneity and sometimes transient nature of the amyloid aggregates, making the application of highresolution structural techniques highly challenging, 31 important information has been achieved by means of X-ray diffraction studies, ${ }^{32-34}$ atomic force microscopy, ${ }^{35}$ cryo-electron microscopy, ${ }^{36,37}$ Fourier-transform infrared (FTIR) spectroscopy, ${ }^{38-41}$ solid-state NMR spectroscopy ${ }^{42-44}$ and $\mathrm{H} / 2 \mathrm{H}$ exchange analyzed by NMR or mass spectrometry (MS). ${ }^{45-48}$ Recently, limited proteolysis has been exploited successfully to analyze aspects of fibril formation by a number of amyloidogenic proteins, including the $\mathrm{A} \beta$ peptide, ${ }^{49} \alpha$-synuclein, ${ }^{50}$ Ure2p, ${ }^{51,52} \mathrm{PI} 3-\mathrm{SH}^{53}$ and bovine $\alpha$-lactalbumin. ${ }^{41}$ The rationale behind this approach is that proteolytic cleavage generally occurs at flexible regions of the polypeptide chain devoid of hydrogen bonded regular secondary structure such as $\alpha$-helices and $\beta$-strands. ${ }^{54-56}$ Indeed, limited proteolysis experiments have been used successfully to obtain valuable information regarding many features of structure and dynamics of both native and partly folded proteins. ${ }^{57}$

In the present study, amyloid fibrils formed by human lysozyme at low $\mathrm{pH}$ were digested by pepsin and the resulting protease-resistant protein core identified by MS analysis. Lysozyme fibrils before and after proteolysis have been analyzed by FTIR spectroscopy, in order to estimate the effect of proteolysis on the secondary structure content of the fibrils. Our results indicate that in some fibrils the entire 130 residue chain of lysozyme is protected from proteolysis, but in most cases only a relatively limited part of the chain is involved in the fibril core, since pepsin can cleave off the $\mathrm{N}$ and C-terminal segments of the protein in the amyloid fibrils. This study emphasizes further the value of limited proteolysis as a technique that can lead to useful structural information even for high molecular mass protein complexes, such as amyloid aggregates, and in this specific case provides important information about the core structure of the lysozyme fibrils.

\section{Results}

\section{Formation and characterization of human lysozyme fibrils}

In order to generate fibrils from human lysozyme, a $1 \mathrm{mM}$ solution of deuterated lysozyme was incubated for eight days with stirring at $45^{\circ} \mathrm{C}$ in $\mathrm{D}_{2} \mathrm{O}$ (pD 1.5). The deuteration step was important in order to produce fibril samples amenable to analysis by FTIR spectroscopy. The kinetics of aggregation of lysozyme were monitored by following the increase in the thioflavin T (ThT) fluorescence emission of aliquots removed from the reaction mixture at different time-points. ${ }^{10}$ The experimental data points fit to a sigmoidal curve, indicating the presence of an initial lag phase of about four days, followed by a rapid growth phase that reaches a plateau at eight days (Figure 1(a)). Transmission electron microscopy revealed that the fibrils produced in this way have typical amyloid morphology (Figure 1(b)), being unbranched, with a length of up to $1 \mu \mathrm{m}$ and a diameter of $\sim 8-10 \mathrm{~nm}$, and are composed of two or more protofilaments twisted around each other. There was no evidence from these experiments for significant quantities of non fibrillar aggregates.

The lysozyme fibrils were purified from nonaggregated soluble material by ultracentrifugation. At least $90 \%$ of the total lysozyme content of the initial solution was found in the pellet, as assessed by UV measurement of the supernatant, indicating that almost all protein material has aggregated. The 

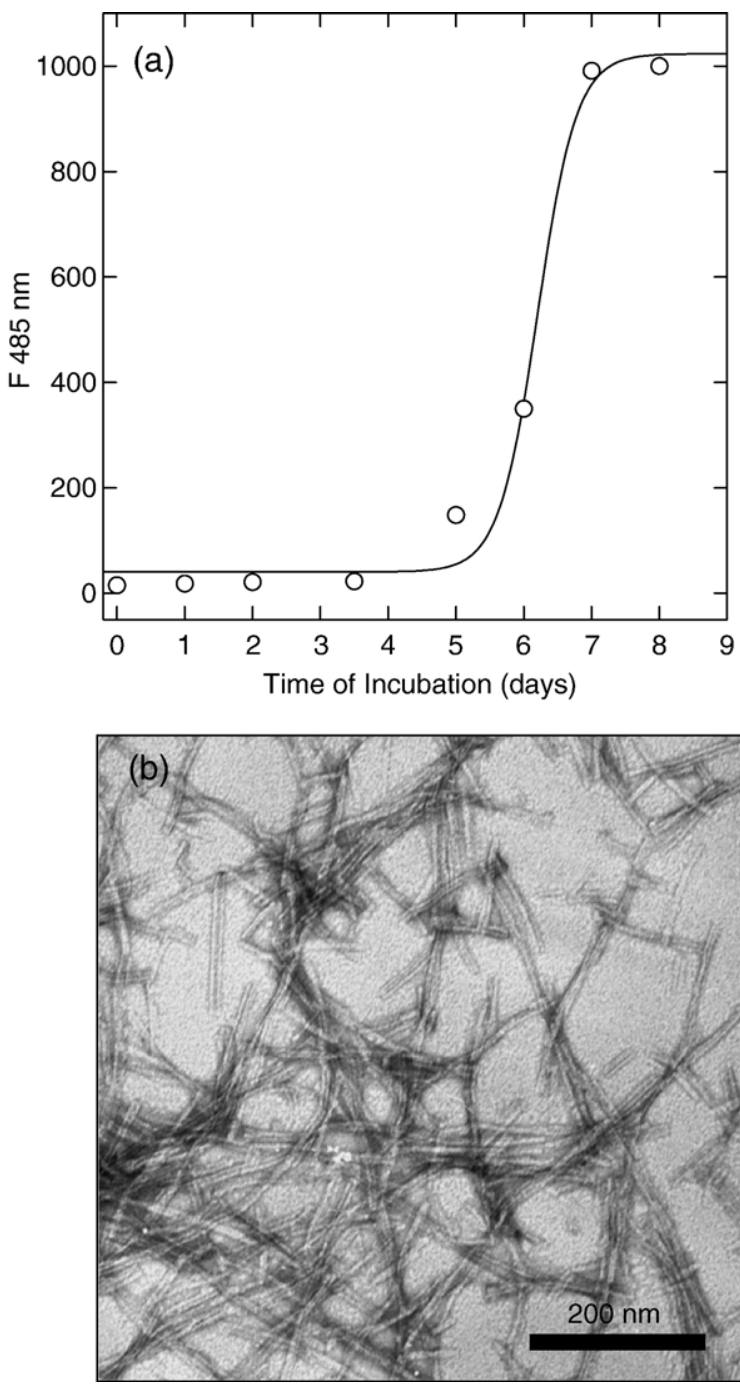

Figure 1. (a) Aggregation of human lysozyme in $32 \mathrm{mM}^{2} \mathrm{HCl}(\mathrm{pD} 1.5)$ at $45^{\circ} \mathrm{C}$, with stirring, monitored by the thioflavin T (ThT) binding assay. Aliquots $(4 \mu \mathrm{l})$ of the protein solution, incubated for the lengths of time indicated, were added to a $25 \mu \mathrm{M}$ solution $(496 \mu \mathrm{l})$ of ThT in $25 \mathrm{mM}$ phosphate buffer ( $\mathrm{pH}$ 6.0). The excitation wavelength was fixed at $440 \mathrm{~nm}$ and the fluorescence emission was collected at $485 \mathrm{~nm}$. (b) Electron micrograph of lysozyme fibrils obtained after incubation for eight days.

morphology and composition of the species in the pellet and supernatant were checked by transmission electron microscopy and by reverse phase (RP)HPLC, respectively. The fibrils in the pellet had morphological features the same as those of fibrils before purification (see Figure 1(b)); in the supernatant, by contrast, only occasional small globular aggregates were observed (not shown). In order to conduct the RP-HPLC analysis, the pellet and supernatant were treated with $7.4 \mathrm{M}$ guanidine hydrochloride $(\mathrm{GdnHCl})$ in order to dissolve all the aggregates, following a procedure previously used for hen lysozyme fibrils. ${ }^{29}$ The protein material eluting in the main chromatographic peaks was then analyzed by electrospray ionization (ESI) mass spectrometry (MS). Figure 2 (top, left) shows that the pellet of fibrils is composed mainly of full-length lysozyme (residues 1-130), accompanied by small amounts of other species, notably 1-102/103-130 and 50-102. These two latter species are derived from the acid-mediated hydrolysis of the peptide bonds Asp49-Arg50 and Asp102-Pro103 (Figure 2, bottom); such Asp-X peptide bond fission is known to occur within proteins exposed to low $\mathrm{pH}$ and relatively high temperatures. ${ }^{29,58,59}$ It is important to note that, whereas fragment $50-102$ is present in the pellet, the complementary fragment species 1-49/ 103-130 remains in soluble form in the supernatant (Figure 2, top right). Interestingly, although preparations of hen lysozyme were found to be degraded significantly at $\mathrm{pH} 2.0,{ }^{29}$ the human variant showed much less hydrolysis under the conditions used here, an observation likely to result from the increased rate of aggregation caused by stirring the solution, making it possible to use a lower temperature $\left(45^{\circ} \mathrm{C}\right.$ versus $\left.65^{\circ} \mathrm{C}\right)$ for inducing protein aggregation.

\section{Mapping the conformation of lysozyme in amyloid fibrils by proteolysis}

Lysozyme is a very stable protein and, therefore, very resistant to proteolysis in its native state. ${ }^{60} \mathrm{In}$ this study, proteolysis of the monomeric and fibrillar protein by pepsin was achieved under rather harsh denaturing conditions, such as pD 2.0 and $57^{\circ} \mathrm{C}$ for several hours. The pellet obtained by ultracentrifugation of lysozyme fibrils was suspended in ${ }^{2} \mathrm{H}_{2} \mathrm{O}$ at pD 2.0 and incubated at $57{ }^{\circ} \mathrm{C}$ with pepsin at an enzyme to substrate $(\mathrm{E}: \mathrm{S})$ ratio of $1: 30(\mathrm{w} / \mathrm{w})$. A relatively large amount of protease relative to lysozyme was used in order to hasten the proteolytic

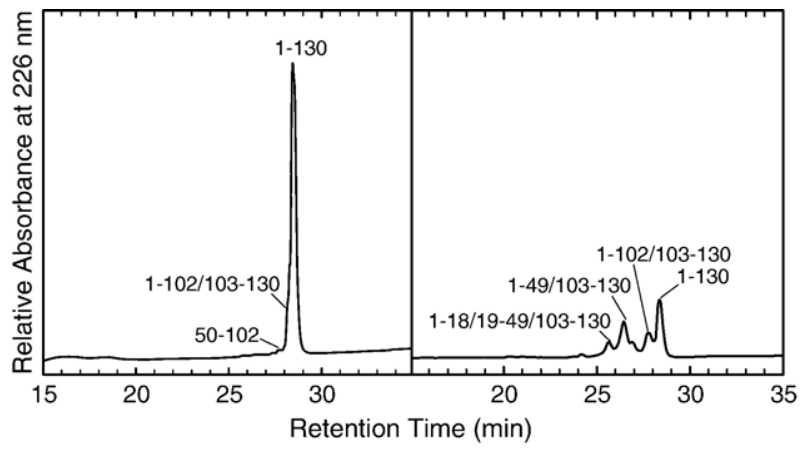

KVFERCELAR TLKRLGMDGY RGISLANWMC LAKWESGYNT RATNYNAGDR STDYGIFQIN SRYWCNDGKT PGAVNACHLS $\stackrel{70}{80}$ CSALLQDNIA DAVACAKRVV 100 RDPQGIRAWV AWRNRCQNRD VRQYVQGCGV

Figure 2. Composition of lysozyme fibrils obtained after incubation at $\mathrm{pD} 1.5$, for eight days at $45^{\circ} \mathrm{C}$, with stirring. Top: RP-HPLC chromatograms of the pellet (left) and the supernatant (right) obtained after ultracentrifugation of the fibrils and their dissolution in $7.4 \mathrm{M} \mathrm{GdnHCl}$ (see Materials and Methods). The identity of the various protein species was determined by ESI MS and is given by the labels near the chromatographic peaks. Bottom: Amino acid sequence of the 130 residue chain of human lysozyme. ${ }^{86}$ 
reaction and hence to minimize any dissolution of the fibrils and/or degradation phenomena. Pepsin was chosen because of its broad specificity; ${ }^{61}$ the cleavage sites are not expected to be dictated by the amino acid sequence, but by the conformational and dynamical features of the polypeptide chain. The samples of the digested fibrils were subjected to ultracentrifugation, and the pellets resulting were solubilized in 7.4 M GdnHCl and analyzed by RPHPLC. The digested fibrils show a morphology quite similar to that of the undigested fibrils (Figure 3(a), inset), and indeed they exhibit the typical amyloid morphology of long, unbranched and twisted structures, with a diameter of $\sim 7-10 \mathrm{~nm}$. However, RP-HPLC analysis of the fibrils digested for $2 \mathrm{~h}$ with pepsin (Figure 3(a)) revealed that two protein fragments, 26-123 and 32-108, are present, as well as the 130 residue wild-type protein, and remain tightly associated within the fibrils. The same composition was observed when the proteolysis of fibrils was conducted for different lengths of time and up to $24 \mathrm{~h}$ (not shown), indicating that the segment $32-108$ is the minimal region of the lysozyme sequence that is resistant to proteolysis. Some of the lysozyme molecules in the fibrils have therefore been cleaved firstly at peptide bonds Leu25-Ala26 and Gln123-Tyr124, leading to the loss of the two-chain species 1-25/124-130, where the fragments are connected together by the disulfide bond Cys6-Cys128 of the protein (Figure 3(d)). Subsequently, the peptide bonds Leu31-Ala32 and Arg108-Trp109 must be cleaved and fragment species 26-31/109-123, containing the disulfide bond Cys30-Cys116, is therefore released. The extent of proteolysis in the fibrils was calculated from the areas of the chromatographic peaks in the RP-HPLC chromatogram shown in Figure 3(a), and the combined quantity of the two fragments (26-123

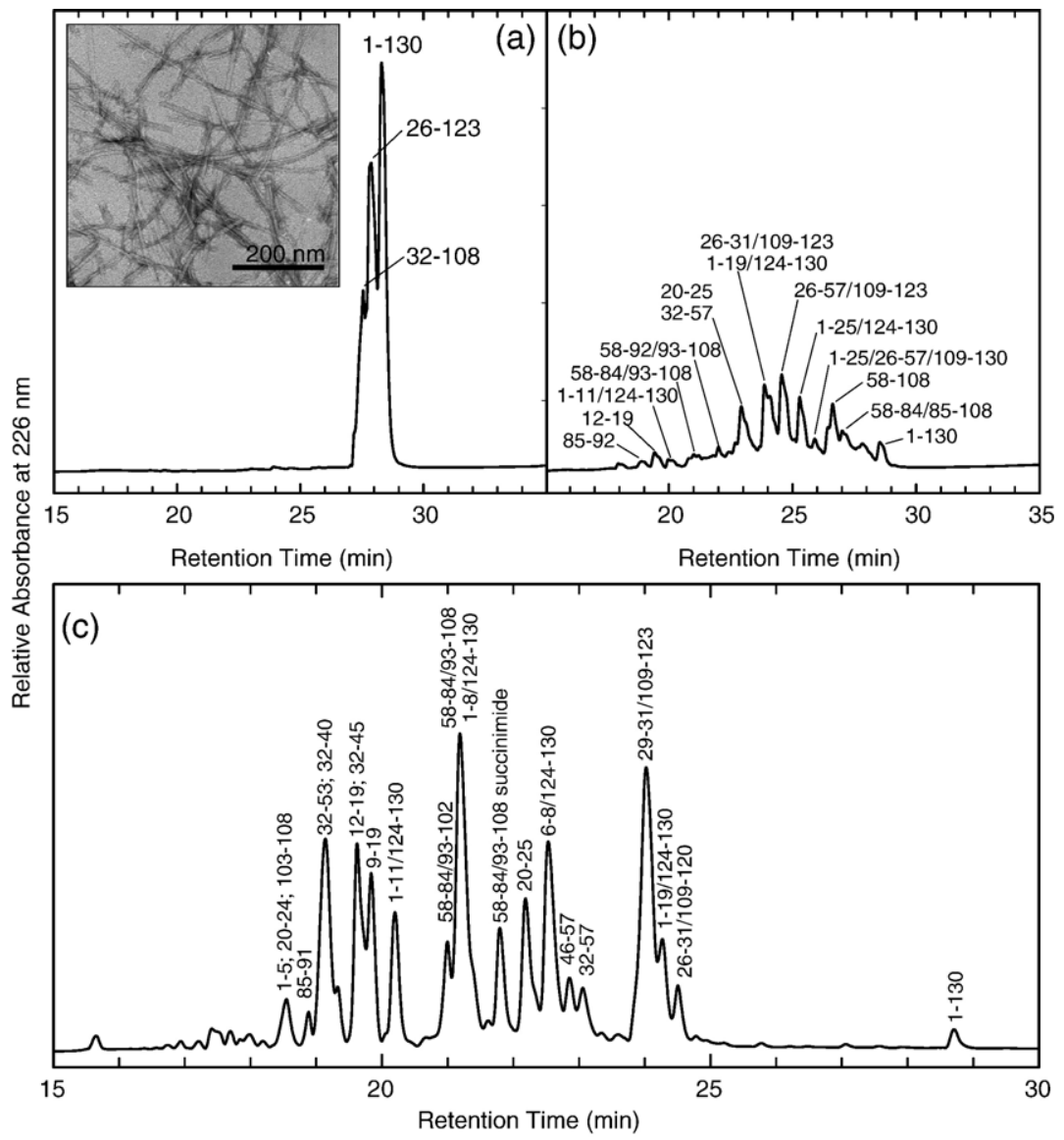

(d)

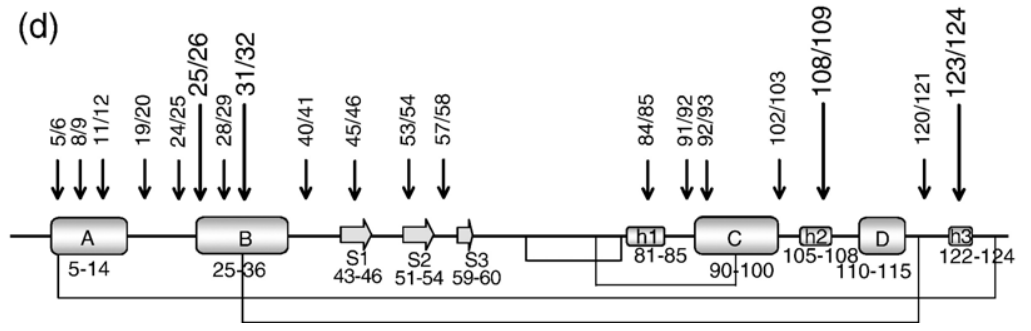

Figure 3. Proteolysis of fibrillar and monomeric human lysozyme. (a) and (b) Proteolysis of purified lysozyme fibrils. RP-HPLC chromatograms of (a) the pellet and (b) the supernatant obtained by ultracentrifugation of lysozyme fibrils digested for $2 \mathrm{~h}$ at $57{ }^{\circ} \mathrm{C}$ with pepsin at an E:S ratio of 1:30 (w/ $\mathrm{w})$ at $\mathrm{pH}$ 2.0. The pellet and the supernatant obtained by ultracentrifugation of the fibrils after proteolysis were each dissolved in 7.4 $\mathrm{M} \mathrm{GdnHCl}$ and then analyzed by RP-HPLC (see Materials and Methods), and the identity of the various protein species was determined by ESI MS. The fragment species 1-102/103-130 and 50-102 that are present in the undigested lysozyme fibrils (see Figure 2, top left) were found in the digested pellet but in negligible quantities: these species are not indicated here. (a) Inset: Electron micrograph of lysozyme fibrils after proteolysis. (c) Proteolysis of monomeric lysozyme. RP-HPLC chromatogram of the peptic digestion of soluble lysozyme performed in $10 \mathrm{mM}$ ${ }^{2} \mathrm{HCl}(\mathrm{pD} 2.0)$ for $2 \mathrm{~h}$ at $57{ }^{\circ} \mathrm{C}$, with an E:S ratio of 1:30 (w/w). The two-chain peptide 58-84/93-108 bears a succinimide moiety at position Asp67-Gly68 as a result of the cyclization of the Asp side-chain at low $\mathrm{pH}$. (d) A representation of the secondary structure of human lysozyme. ${ }^{25,91}$ The boxes indicate the location along the 130 residue chain of the protein of $\alpha$-helices A$\mathrm{D}$, the $3_{10}$ helical elements h1-h3 and the three $\beta$-strands S1-S3. The connectivity of the four disulfide bonds Cys6-Cys128, Cys30-Cys116, Cys65-Cys81 and Cys77-Cys95 of the protein are indicated by continuous lines. Short arrows indicate the pepsin cleavage sites on the monomeric protein, whereas the longer lines show the pepsin cleavages of lysozyme in the fibrils. 
and $32-108)$ accounts for $\sim 60 \%$ of the lysozyme molecules present in the fibrils, the remainder being the full-length protein 1-130.

Analysis of the supernatant of the proteolysis mixture showed, by contrast, only trace amounts of intact lysozyme but a variety of protein fragments (Figure 3(b)). Among the latter are the species that are complementary to the fragments found in the digested fibrils, i.e. 1-25/124-130 and 26-31/109123, plus fragments 1-19/124-130, 20-25, 1-11/124130 and 12-19 that derive from additional cleavages of the larger fragments. Other fragments are found in the supernatant that are likely to be derived from the peptic digestion of intact lysozyme following a small amount of dissolution of the fibrils during proteolysis. In order to examine whether lysozyme fibrils are stable in the solution conditions used for peptic digestion, or if they partially degrade, fibrils were incubated at $57^{\circ} \mathrm{C}$ in $10 \mathrm{mM}^{2} \mathrm{HCl}(\mathrm{pD} 2.0)$ for up to $4 \mathrm{~h}$, but in the absence of pepsin. The samples were then subjected to ultracentrifugation and the supernatant and pellet treated with 7.4 M GdnHCl. RPHPLC analyses revealed that the compositions of the supernatant and the pellet obtained in this experiment are identical with that of the fibrils before proteolysis (not shown). Therefore, for these incubation times at least, the acidic buffer does not cause significant chemical modification of the protein. From UV absorbance measurements of the supernatant, however, approximately $10 \%$ and $12 \%$ of the lysozyme in the fibrils after $2 \mathrm{~h}$ and $4 \mathrm{~h}$ of incubation, respectively, was found to dissociate from the fibrils and remain soluble in the supernatant. Different populations of the 130 residue chain of lysozyme could therefore be cleaved by the proteolytic probe, i.e. both the aggregated protein within the fibrils and the soluble protein dissociated from the fibrils. Indeed, it has been demonstrated that protein molecules can dissociate within the fibril population, illustrating the dynamic nature of amyloid fibrils. ${ }^{48}$

A proteolysis experiment was conducted on freshly dissolved monomeric lysozyme under the same proteolysis conditions used for the digestion of fibrils (pD 2.0, $57^{\circ} \mathrm{C}, 2 \mathrm{~h}$ ). Figure 3(c) indicates that lysozyme is almost completely degraded by pepsin under these conditions, since only a small peak corresponding to the intact protein is still visible in the RP-HPLC chromatogram. The protein is evidently cleaved by pepsin at many sites along its 130 residue chain, and the relatively short fragments produced in this way have much lower RP-HPLC retention times than the larger fragments that originate from the proteolysis of the fibrils (Figure $3(d)$ ). This finding indicates that the fragments observed in the present study must have arisen from lysozyme in the fibrillar rather than solution state.

\section{Conformational analysis of lysozyme fibrils by FTIR}

The lysozyme fibrils before and after digestion with pepsin were analyzed by FTIR spectroscopy in order to investigate the features of the secondary structure of the protein molecules within amyloid aggregates. Figure 4(a) shows the FTIR spectrum of the pellet produced by ultracentrifugation of the undigested fibrils, recorded in $10 \mathrm{mM}^{2} \mathrm{HCl}$, (pD 2.0). The spectral envelope can be deconvoluted into four main components, each of which can be associated with specific elements of secondary structure. The bands $1(32 \%)$ and $4(7 \%)$ centered at $1614 \mathrm{~cm}^{-1}$ and $1682 \mathrm{~cm}^{-1}$, respectively, are typical of amyloid fibrils absorption at $\sim 1635 \mathrm{~cm}^{-1}$ and $1675 \mathrm{~cm}^{-1}$, characteristic of antiparallel $\beta$-sheet structure, shift to 1611$1630 \mathrm{~cm}^{-1}$ and $\sim 1684 \mathrm{~cm}^{-1}$, respectively, in cross- $\beta$ amyloid aggregates. ${ }^{62,63}$ However, the main contri-

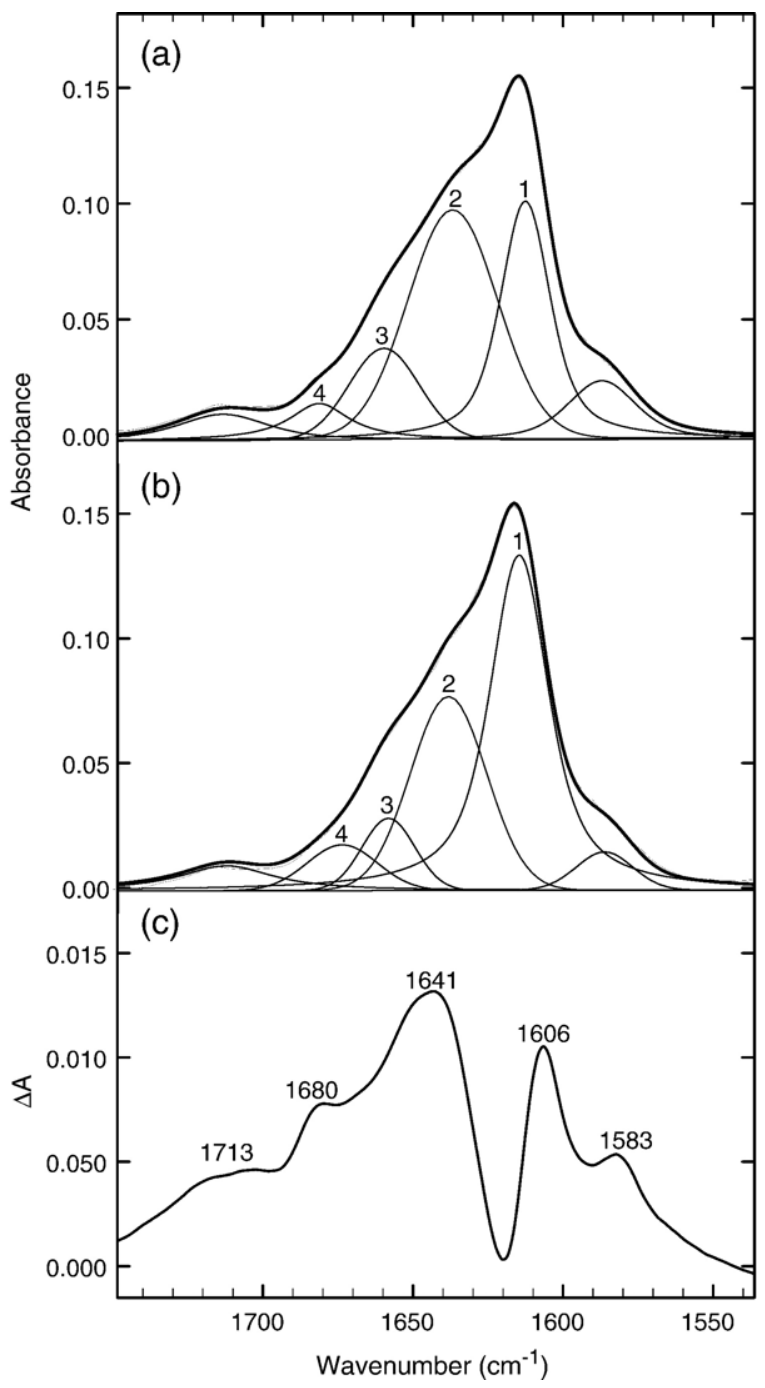

Figure 4. FTIR analysis of lysozyme fibrils (a) before and (b) after proteolysis and (c) the difference spectrum. (a) and (b) The FTIR spectra were obtained in $10 \mathrm{mM}^{2} \mathrm{HCl}$ (pD 2.0) at room temperature and fitted with Gaussian and Lorentzian curves. The peak position of the amide I band components was deduced from the second derivative spectra. The sum of the fitted curves is shown as a continuous heavy line, closely overlapping the experimental trace, which is shown as a thin line. (c) The difference spectrum obtained by subtracting the FTIR spectrum of digested fibrils shown in (b) from that of undigested fibrils shown in (a). 
bution (47\%) to the FTIR spectrum is given by the broad band centered at $1640 \mathrm{~cm}^{-1}$ (band 2), which is associated with disordered structure. ${ }^{64,65}$ In addition, there is a contribution at $1659 \mathrm{~cm}^{-1}$ associated with turns and/or $\alpha$-helix (band 3, 14\%). Indeed, the FTIR spectrum of fibrils derived from the D67H amyloidogenic mutant of lysozyme suggests that the predominant $\beta$-structure is accompanied by some residual helical structure. ${ }^{20}$

In the FTIR spectrum of the digested fibrils, the same structural components can be observed but at different relative intensities (see Figure 4(b)). The major difference is that bands 2 and 3, attributable to disordered structure, turns and helices, are decreased significantly in their intensity $(32 \%$ and $8 \%$, respectively) relative to those from the $\beta$-sheet structure. The difference in the secondary structure content between the fibrils before and after proteolysis can be seen particularly clearly in the difference spectrum obtained by subtracting the spectrum of the proteolyzed fibrils from that of the undigested ones (Figure $4 \mathrm{C}$ ). The main peak in the difference spectrum centered at $1641 \mathrm{~cm}^{-1}$ is associated with a decrease in disordered structure in the proteolyzed fibrils. In addition to the change associated with secondary structure, the spectral components resulting from side-chain signals are reduced in their intensity in the digested fibrils, in particular those resulting from the absorption of the carbonyl and carboxylic groups of aspartic acid $\left(1583 \mathrm{~cm}^{-1}\right.$ and $1713 \mathrm{~cm}^{-1}$ ), of the $\mathrm{OH}$ group of tyrosine and of the $\mathrm{CN}_{3} \mathrm{H}_{5}^{+}$side-chain group of arginine $\left(1606 \mathrm{~cm}^{-1}\right){ }^{66}$ In the proteolyzed fibrils, there is also a decrease in the signal intensity at $1680 \mathrm{~cm}^{-1}$, attributable to antiparallel $\beta$-sheet elements, suggesting that the core structure of lysozyme fibrils could have a parallel $\beta$-sheet arrangement. Overall, therefore, the FTIR data show that the main structural variation caused by proteolysis of the fibrils is a reduction of the content of disordered and/or helical structure.

\section{Discussion}

In this study, the conformational features of human lysozyme when embedded into amyloid fibrils have been examined by using proteolysis and FTIR measurements. The aggregation conditions were optimized in order to obtain fibrils containing full-length lysozyme on a reasonable time-scale. The process was carried out at $\mathrm{pD} 1.5,45^{\circ} \mathrm{C}$, where $\mathrm{CD}$ data suggest that a partially unfolded state of human lysozyme is significantly populated at equilibrium $(\sim 35 \%)$, while about $60 \%$ of the protein is still native, and the remaining $5 \%$ is highly unfolded. ${ }^{67}$ The protein aggregation process is accelerated greatly by stirring the protein solution, so that relatively homogeneous fibrils are formed and Asp- $X$ fragmentations occurring at low $\mathrm{pH}$ are avoided. ${ }^{29}$ The only fragment found in the fibrils along with the full-length protein, before pepsin treatment, corresponds to the sequence 50-102, present at low levels, that includes a part of the $\beta$ - domain and helix $\mathrm{C}$ of the native protein (see Figure $3(d)$ ). This species is similar to several fragments found previously in the fibrils of hen lysozyme obtained at $\mathrm{pH} 2.0$ and $65{ }^{\circ} \mathrm{C}$, derived by Asp-X hydrolysis events. ${ }^{29}$

Human lysozyme fibrils treated with pepsin were not digested completely even after a prolonged reaction time. This result is in accord with the finding that amyloid fibrils are usually very resistant to proteolysis ${ }^{40,53,68,69}$ and that their architecture is formed by several twisted protofilaments. ${ }^{69,70}$ As a consequence, any protein molecules buried on the inner sides of the protofilaments might not be accessible to a relatively large conformational probe such as pepsin. ${ }^{49}$ However, a substantial proportion $(\sim 60 \%)$ of molecules in the fibrils examined here have been digested by pepsin, revealing that they possess some segments of the polypeptide chain that are flexible enough to interact with the active site of the protease. Nevertheless, the fibrils experience proteolysis at very few sites in the sequence, despite the fact that there are many potential peptic sites distributed along the protein sequence. Moreover, substantial differences have been observed between the proteolytic pattern of monomeric soluble lysozyme and that of lysozyme in the fibrils under the same experimental conditions (Figure 3). Of particular importance is the observation that the fragment species 26-123 and 32-108 are generated by peptic proteolysis, but remain incorporated into the fibrils. These fragments are relatively large, whereas those produced after proteolysis of monomeric lysozyme are much shorter. This result shows that the polypeptide chain of lysozyme in the aggregates is far less accessible to the protease than it is in the soluble form. The main finding from the proteolysis data, however, is the absence of cleavage sites in the central region 32-108 of the protein sequence, indicating that the complementary fragments 1-25/124-130 and 1-31/109130 , containing the $\mathrm{N}$ and $\mathrm{C}$-terminal segments of the protein and linked by the two disulfide bonds Cys6-Cys128 and Cys30-Cys115, must have dissociated from the network of fibrils following proteolysis and been cleaved further at positions Thr11-Leu12 and Gly19-Tyr20. Therefore, these regions of the protein are not tightly associated in the fibril core and must be structurally flexible or highly unfolded. Although 32-108 is the minimal sequence obtained by proteolysis, the polypeptide chain involved in the fibril core could be even shorter, as a stretch of about ten amino acids residues is necessary to allow protease interaction. ${ }^{56}$

Since pepsin removes the $\mathrm{N}$ - and C-terminal segments of lysozyme in the fibrils, it can be concluded that the region 32-108 of lysozyme forms the major cross $\beta$-structure core of the fibril and that the rest of the 130-residue chain is, at least in the majority of molecules, largely unstructured and/or weakly packed. The fact that the undigested and digested lysozyme fibrils show essentially the same morphology, as indicated by transmission electron microscopy (see Figure 3(a)), can be 
explained by considering that the unstructured regions are likely to be poorly stained due to their lack of close-packing and/or hydrophilic nature. Therefore, only the core of the lysozyme fibrils is expected to be revealed by electron microscopy, while the disorganised regions of the protein molecules located outside the well-ordered fibrils are likely to not be visible. This interpretation is similar to that given in the recent analysis of the fibril morphology of fragments of tau protein as compared to that of the whole protein molecule. ${ }^{71}$ The results of this study are in line with similar observations indicating that the entire sequence of a protein molecule need not be incorporated in the amyloid core structure. ${ }^{31,33,36,37,49,50,72}$ For example, only the central region $31-109$ of the 140 amino acid residue chain of $\alpha$-synuclein is involved in the fibrillar $\beta$-sheet core, as deduced from proteolysis experiments with proteinase $K, 50$ and in the case of the $A \beta(1-40)$ peptide, some 12 to 16 residues of the $\mathrm{N}$-terminal region of the peptide appear to be excluded from the fibril structure and therefore prone to proteolysis. ${ }^{49}$

The pepsin-resistant segment 32-108 encompasses the $\beta$-sheet and helix $C$ of native lysozyme (Figure $3(d)$ ) and corresponds to the region, approximately residues 31-104 that readily undergoes local unfolding in the amyloidogenic variants I56T and D67H of human lysozyme ${ }^{21,28}$ and in the wild-type protein under more extreme conditions. ${ }^{73}$ Moreover, this region also encompasses fragment 57-107 that was found to be highly amyloidogenic in hen lysozyme. $^{29}$ In addition, a camel antibody fragment that binds to 14 residues located in the loop between helices $A$ and $B$, in the long loop within the $\beta$-domain and in the C-helix was found to be able to restore the global cooperativity of mutant lysozymes I56T and $\mathrm{D} 67 \mathrm{H}$, therefore preventing the aggregation process of these mutants. ${ }^{21,74}$ These data suggest that the region involved in the cooperative local unfolding of the molecule, and which is also the most amyloidogenic part of the sequence, is a key factor in determining the specific structure of the lysozyme fibrils. Interestingly, proteolysis experiments conducted at $45{ }^{\circ} \mathrm{C}$ on monomeric human lysozyme at $\mathrm{pD} 1.5$; on the conformational state of the protein that is the precursor to the fibrils, show that the first peptide bonds that are cleaved by pepsin are Phe57Gln58 and Ala108-Trp109, located in the $\beta$-domain and in the $3_{10}$ helix between helices $C$ and $D$, respectively (not shown). These results support the conclusion that unfolding of these segments of the chain triggers the formation of the amyloid structure by human lysozyme. Indeed, it is very likely that partial unfolding of a globular protein will often be a key factor in initiating the aggregation process. Protein destabilization, by the addition of a denaturant, low $\mathrm{pH}$, high temperature or amino acid substitution, can lead to an increased population of partially unfolded monomeric protein molecules that are key species in the initiation of fibril formation. Such partially unfolded conformations presumably enable the specific intermolecular inter- actions that are necessary for protein oligomerization and fibrillation. ${ }^{20,75-79}$

The incomplete digestion of lysozyme fibrils by pepsin can be explained on the basis that the non- $\beta$ sheet segments of specific regions of the molecules in the fibrils are so tightly packed in the structure that they are not accessible to the protease. There is also evidence that the fibrils exhibit a significant degree of polymorphism, as a population of protein molecules (approximately 40\%) appears to be completely resistant to proteolysis and, therefore, could in principle have their entire polypeptide chain involved in the highly organized core structure of the fibrils. This hypothesis appears to be unlikely, however, as the process of aggregation of the protein was conducted whilst stirring the solution, and electron microscopy suggests that the fibrils are relatively homogeneous, at least in terms of their morphology. In addition, the FTIR spectrum of the proteolyzed fibrils indicates the presence of relatively unstructured regions that have not been cleaved by the protease. This finding suggests instead that pepsin may not be able to gain access to all the disorganized or loop regions within the fibrils, perhaps because they are buried in the rigid structure of the fibril, by the packing of the constituent protofilaments. Interestingly, the inaccessibility of approximately $50 \%$ of flexible regions of proteins in amyloid fibrils has been seen elsewhere, ${ }^{45,80}$ a fact that could be related to the idea that a double sheet could be a common building block of the amyloid structure. ${ }^{34,81}$

Analysis of the aggregation properties of peptides corresponding to fragments of a protein provides information about the relative propensity of different regions of a protein sequence to form the amyloid structure, and hence is useful for probing the physicochemical determinants of aggregation. ${ }^{41,82,83}$ The approach used in the present study is complementary to this approach but is based, instead, on the identification of the core regions of an intact protein after its conversion into an amyloid fibril. In this way, we have obtained conformational information relating to lysozyme in its fibrillar context, taking into account all the structural constraints, such as the native disulfide bonds and other long-range interactions that influence the way that the protein converts into the amyloid structure.

Detailed knowledge of the structure of the wellordered protein aggregates that constitute amyloid deposits is essential for understanding the nature of protein homeostasis and for developing insight into the molecular aspects of protein aggregation diseases, including neurodegenerative disorders such as Alzheimer's and Parkinson's disease. An increasing variety of physicochemical techniques is being used for analyzing protein aggregates and substantial progress is now being made in describing the molecular architectures of amyloid fibrils. ${ }^{31,36}$ The use of conventional analytical approaches is, however, still a major challenge, so that novel and unconventional analytical approaches need to be devised. ${ }^{84}$ Here, we have shown that limited pro- 
teolysis is a technique that can be used successfully to obtain valuable information about the structure and dynamics of proteins in a wide variety of the many states accessible to peptides and proteins. In the case of the human lysozyme fibrils described here, limited proteolysis has proved to be of great value in revealing that the segment of the protein that appears to form the most stable region of the amyloid core structure (residues 32-108) is essentially identical with the region of the native structure that is most susceptible to local unfolding (residues 31-104). ${ }^{21,28}$ This remarkable correlation between the dynamic behavior of the soluble precursor and the structural properties of the protein in an amyloid fibril provides compelling evidence for the hypothesis that partial unfolding of the native structure of lysozyme is a crucial factor in its conversion to the generic amyloid structure. ${ }^{20,27}$

\section{Materials and Methods}

\section{Materials}

Wild-type human lysozyme was expressed as described. ${ }^{3}$ Porcine pepsin and thioflavin-T (ThT) were purchased from the Sigma Chem. Co. (St. Louis, MO). All other chemicals were of analytical reagent grade and were obtained from Sigma or Fluka (Buchs, Switzerland).

\section{Methods}

\section{Preparation and characterization of lysozyme fibrils}

Deuterated lysozyme was prepared by incubating at $81^{\circ} \mathrm{C}$ for $45 \mathrm{~min}$ a $10 \mathrm{mg} / \mathrm{ml}$ protein solution in ${ }^{2} \mathrm{H}_{2} \mathrm{O}$ at $\mathrm{pD}$ 3.8, followed by lyophilization. ${ }^{85}$ Lysozyme fibrils were obtained by stirring a $1 \mathrm{mM}$ deuterated lysozyme solution in $32 \mathrm{mM}^{2} \mathrm{HCl}$ (pD 1.5), at $45^{\circ} \mathrm{C}$ for up to ten days.

In order to confirm the presence of protein fibrils, aliquots of the samples were examined by ThT fluorescence and transmission electron microscopy. The ThT binding assays were performed using a freshly prepared $25 \mu \mathrm{M}$ ThT solution in $25 \mathrm{mM}$ sodium phosphate ( $\mathrm{pH}$ 6.0) that had been passed through $0.45 \mu \mathrm{m}$ pore size filters. Aliquots $(4 \mu \mathrm{l})$ of protein samples containing aggregates were taken at specified times and diluted into the ThT buffer (final volume $500 \mu \mathrm{l}$ ). Fluorescence emission measurements were conducted at $25^{\circ} \mathrm{C}$ using an excitation wavelength of $440 \mathrm{~nm}$ and recording the ThT fluorescence emission at $485 \mathrm{~nm}$. Electron micrographs were taken with a JEOL model JEM1010 instrument operating at $80 \mathrm{kV}$. Samples for electron microscopy were diluted 20 times and a drop of the solution was placed on a Formvar-coated nickel grid (400-square mesh, Agar Scientific), followed by a drop of $2 \%$ (w/v) uranyl acetate. After a few seconds, the grid was washed with deionized water (MilliQ).

Separation of lysozyme fibrils from monomers and soluble oligomers was performed by ultracentrifugation with a Beckman-Coulter MLA-130 ultracentrifuge (model Optima MAX-E, Palo Alto, CA) at $4{ }^{\circ} \mathrm{C}$ for $1.5 \mathrm{~h}$ at $90,000 \mathrm{rpm}(380,000 \mathrm{~g})$. The quantity of fibrils precipitated in the pellet was estimated by measuring the concentration of the protein in the supernatant, using the extinction coefficient of the intact protein, as below.

\section{Proteolysis of monomeric and fibrillar lysozyme}

Monomeric lysozyme or purified lysozyme fibrils were subjected to proteolysis in $10 \mathrm{mM}{ }^{2} \mathrm{HCl}(\mathrm{pD} 2.0)$ at $57^{\circ} \mathrm{C}$, using pepsin at an E:S ratio of 1:30 (w/w). For peptic digestion of fibrils, lysozyme fibrils were collected by ultracentrifugation and the pellet was suspended in the proteolysis buffer at $\sim 10 \mathrm{mg} / \mathrm{ml}$. After proteolysis, the fibril sample was subjected to ultracentrifugation again and both pellet and supernatant were dissolved in 7.4 M $\mathrm{GdnHCl}$, mixed overnight and subsequently analyzed by RP-HPLC. All RP-HPLC analyses were performed on a Vydac $C_{18}$ column $(4.6 \mathrm{~mm} \times 150 \mathrm{~mm}$; The Separations Group, Hesperia, CA) eluted with a linear gradient of acetonitrile containing $0.1 \%(\mathrm{v} / \mathrm{v})$ trifluoroacetic acid from $5 \%$ to $22 \%$ in $5 \mathrm{~min}$ and from $22 \%$ to $50 \%$ in $17 \mathrm{~min}$, at a flow-rate of $0.6 \mathrm{ml} / \mathrm{min}$. The effluent from the column was monitored by measurement of the absorbance at $226 \mathrm{~nm}$. The identity of protein fragments was assessed by electrospray mass spectrometry (ESI-MS) with a Q-Tof Micro mass spectrometer (Micromass, Manchester, UK). Since many proteolytic fragment species of lysozyme are crosslinked by disulfide bonds, these species were reduced with tris(2-carboxyethyl)phosphine (TCEP) in order to cleave the disulfide bonds, and the individual peptides were then purified by RP-HPLC and analyzed by ESI-MS

\section{Spectroscopic measurements}

Protein concentrations were determined by absorption measurements at $280 \mathrm{~nm}$ on a double-beam Lambda-20 spectrophotometer from Perkin Elmer (Norwalk, CT). The extinction coefficient $(\varepsilon \mathrm{mg} / \mathrm{ml})$ at $280 \mathrm{~nm}$ for lysozyme was evaluated on the basis of its amino acid composition, 86,87 and was 2.49 .

Fourier-transform infrared (FTIR) spectra were recorded at $20-22{ }^{\circ} \mathrm{C}$ using a Perkin Elmer $1720 \times$ spectrometer, purged with a continuous flow of $\mathrm{N}_{2}$ gas. Pellets from the ultracentrifugation of lysozyme fibrils were suspended in $10 \mathrm{mM}^{2} \mathrm{HCl}$ (pD 2.0) to give a concentration of $\sim 10 \mathrm{mg} /$ $\mathrm{ml}$. Protein samples were placed between a pair of $\mathrm{CaF}_{2}$ windows separated by a $50 \mu \mathrm{m}$ mylar spacer. For each protein sample, 50 interferograms were accumulated at a spectral resolution of $2 \mathrm{~cm}^{-1}$. The spectra were analyzed using the Grams 32 program version 4.14 (Galactic Industries Corporation, Salem, NH). Buffer spectra were recorded under conditions identical with those used for protein samples and subtracted from the protein spectra. The second derivative of the amide I band was used to identify the different spectral components. Thereafter, curve fitting was performed with Gaussian and Lorentzian lineshapes, and with bandwidths varying between $15 \mathrm{~cm}^{-1}$ and $20 \mathrm{~cm}^{-1} .88$ The heights, widths and positions of each band were optimized iteratively. ${ }^{89,90}$ The difference spectrum was calculated by subtracting the spectrum of digested lysozyme fibrils from that of undigested fibrils.

\section{Acknowledgements}

We thank Mr Vittorio Moretto for assistance in recording FTIR spectra and Dr Marco Crisma for help in the interpretation of the data. The assistance of $\mathrm{Mr}$ Giuseppe Tognon in the use of the transmission electron microscope is gratefully acknowledged. We 
are grateful for support from the Italian Ministery of University and Research (PRIN-2004 Project on Aggregation of Protein Fragments and FIRB-2003 Project on Protein Folding and Aggregation), the Leverhulme and Wellcome Trusts and the BBSRC.

\section{References}

1. Kelly, J. W. (1996). Alternative conformations of amyloidogenic proteins govern their behavior. Curr. Opin. Struct. Biol. 6, 11-17.

2. Wetzel, R. (1996). For protein misassembly, it's the " $\mathrm{I}^{\prime}$ decade. Cell, 6, 699-702.

3. Lansbury, P. T., Jr (1999). Evolution of amyloid: what normal protein folding may tell us about fibrillogenesis and disease. Proc. Natl Acad. Sci. USA, 96, 3342-3344.

4. Merlini, G. \& Bellotti, V. (2003). Molecular mechanisms of amyloidosis. N. Engl. J. Med. 349, 583-596.

5. Stefani, M. \& Dobson, C. M. (2003). Protein aggregation and aggregate toxicity: new insights into protein folding, misfolding diseases and biological evolution. J. Mol. Med. 81, 678-699.

6. Selkoe, D. J. (2003). Folding proteins in fatal ways. Nature, 426, 900-904.

7. Koo, E. H., Lansbury, P. T., Jr \& Kelly, J. W. (1999). Amyloid diseases: abnormal protein aggregation in neurodegeneration. Proc. Natl Acad. Sci. USA, 96, 9989-9990.

8. Westermark, P., Benson, M. D., Buxbaum, J. N., Cohen, A. S., Frangione, B., Ikeda, S. et al. (2002). Amyloid fibril protein nomenclature. Amyloid, 9, 197-200.

9. Cooper, J. H. (1974). Selective staining as a function of amyloid composition and structure: histochemical analysis of the alkaline Congo Red, standardized toluidine blue and iodine methods. Lab. Invest. 31, 232-238.

10. LeVine, H. (1993). Thioflavine $\mathrm{T}$ interaction with synthetic Alzheimer's disease beta-amyloid peptides: detection of amyloid aggregation in solution. Protein Sci. 2, 404-410.

11. Guijarro, J. I., Sunde, M., Jones, J. A., Campbell, I. D. \& Dobson, C. M. (1998). Amyloid fibril formation by an SH3 domain. Proc. Natl Acad. Sci. USA, 95, 4224-4228.

12. Chiti, F., Webster, P., Taddei, N., Clark, A., Stefani, M. Ramponi, G. \& Dobson, C. M. (1999). Designing conditions for in vitro formation of amyloid protofilaments and fibrils. Proc. Natl Acad. Sci. USA, 96, 3590-3594.

13. Dobson, C. M. (1999). Protein misfolding, evolution and disease. Trends Biochem. Sci. 24, 329-332.

14. Pepys, M. B., Hawkins, P. N., Booth, D. R., Vigushin, D. M., Tennent, G. A., Soutar, A. K. et al. (1993). Human lysozyme gene mutations cause hereditary systemic amyloidosis. Nature, 362, 553-557.

15. Valleix, S., Drunat, S., Philit, J. B., Adoue, D., Piette, J. C., Droz, D. et al. (2002). Hereditary renal amyloidosis caused by a new variant lysozyme W64R in a French family. Kidney Int. 61, 907-912.

16. Yazaki, M., Farrell, S. A. \& Benson, M. D. (2003). A novel lysozyme mutation Phe57lle associated with hereditary renal amyloidosis. Kidney Int. 63, 1652-1657.

17. Merlini, G. \& Bellotti, V. (2005). Lysozyme: A paradigmatic molecule for the investigation of protein structure, function and misfolding. Clin. Chim. Acta, 357, 168-172.

18. Röcken, C., Becker, K., Fändrich, M., Schroeckh, V.,
Stix, B., Rath, T. et al. (2006). A Lys amyloidosis caused by compound heterozygosity in exon 2 (Thr70Asn) and exon 4 (Trp112Arg) of the lysozyme gene. Hum. Mutat. 27, 119-120.

19. Booth, D. R., Pepys, M. B. \& Hawkins, P. N. (2000). A novel variant of human lysozyme (T70N) is common in the normal population. Hum. Mutat. 16, 180.

20. Booth, D. R., Sunde, M., Bellotti, V., Robinson, C. V., Hutchinson, W. L., Fraser, P. E. et al. (1997). Instability, unfolding and aggregation of human lysozyme variants underlying amyloid fibrillogenesis. Nature, 27, 787-793.

21. Dumoulin, M., Canet, D., Last, A. M., Pardon, E., Archer, D. B., Muyldermans, S. et al. (2005). Reduced global cooperativity is a common feature underlying the amyloidogenicity of pathogenic lysozyme mutations. J. Mol. Biol. 25, 773-788.

22. Kumita, J. R., Johnson, R. J., Alcocer, M. J., Dumoulin, M., Holmqvist, F., McCammon, M. G. et al. (2006). Impact of the native-state stability of human lysozyme variants on protein secretion by Pichia pastoris. FEBS J. 273, 711-720.

23. Morozova-Roche, L. A., Zurdo, J., Spencer, A., Noppe, W., Receveur, V., Archer, D. B. et al. (2000). Amyloid fibril formation and seeding by wild-type human lysozyme and its disease-related mutational variants. J. Struct. Biol. 130, 339-351.

24. De Felice, F. G., Vieira, M. N., Meirelles, M. N., Morozova-Roche, L. A., Dobson, C. M. \& Ferriera, S. T. (2004). Formation of amyloid aggregates from human lysozyme and its disease-associated variants using hydrostatic pressure. FASEB J. 18, 1099-1101.

25. Redfield, C. \& Dobson, C. M. (1990). ${ }^{1} \mathrm{H}$ NMR studies of human lysozyme: Spectral assignment and comparison with hen lysozyme. Biochemistry, 29, 7201-7214.

26. Hooke, S. D., Radford, S. E. \& Dobson, C. M. (1994). The refolding of human lysozyme: A comparison with the structurally homologous hen lysozyme. Biochemistry, 33, 5867-5876.

27. Dumoulin, M., Kumita, J. \& Dobson, C. M. (2006). Normal and aberrant biological self-assembly: Insights from studies of human lysozyme and its amyloidogenic variants. Accts Chem. Res. In press.

28. Canet, D., Last, A. M., Tito, P., Sunde, M., Spencer, A., Archer, D. B. et al. (2002). Local cooperativity in the unfolding of an amyloidogenic variant of human lysozyme. Nature Struct. Biol. 9, 308-315.

29. Frare, E., Polverino de Laureto, P., Zurdo, J., Dobson, C. M. \& Fontana, A. (2004). A highly amyloidogenic region of hen lysozyme. J. Mol. Biol. 23, 1153-1165.

30. Krebs, M. R., Wilkins, D. K., Chung, E. W., Pitkeathly, M. C., Chamberlain, A. K., Zurdo, J. et al. (2000). Formation and seeding of amyloid fibrils from wildtype hen lysozyme and a peptide fragment from the beta-domain. J. Mol. Biol. 14, 541-549.

31. Tycko, R. (2004). Progress towards a molecular-level structural understanding of amyloid fibrils. Curr. Opin. Struct. Biol. 14, 96-103.

32. Sunde, M. \& Blake, C. (1997). The structure of amyloid fibrils by electron microscopy and X-ray diffraction. Advan. Protein Chem. 50, 123-159.

33. Ivanova, M. I., Sawaya, M. R., Gingery, M., Attinger, A. \& Eisenberg, D. (2004). An amyloid-forming segment of beta2-microglobulin suggests a molecular model for the fibril. Proc. Natl Acad. Sci. USA, 101, 10584-10589.

34. Nelson, R., Sawaya, M. R., Balbirnie, M., Madsen, A. O., Riekel, C., Grothe, R. \& Eisenberg, D. (2005). 
Structure of the cross-beta spine of amyloid-like fibrils. Nature, 435, 773-778.

35. Chamberlain, A. K., MacPhee, C. E., Zurdo, J. Morozova-Roche, L. A., Hill, H. A., Dobson, C. M. \& Davis, J. J. (2000). Ultrastructural organization of amyloid fibrils by atomic force microscopy. Biophys. J. 79, 3282-3293.

36. Jiménez, J. L., Guijarro, J. I., Orlava, E., Zurdo, J., Dobson, C. M., Sunde, M. \& Saibil, H. R. (1999). Cryoelectron microscopy structure of an SH3 amyloid fibril and model of the molecular packing. EMBO J. 18, 815-821.

37. Jiménez, J. L., Nettleton, E. J., Bouchard, M., Robinson, C. V., Dobson, C. M. \& Saibil, H. R. (2002). The protofilament structure of insulin amyloid fibrils. Proc. Natl Acad. Sci. USA, 99, 9196-9201.

38. Bouchard, M., Zurdo, J., Nettleton, E. J., Dobson, C. M. \& Robinson, C. V. (2000). Formation of insulin amyloid fibrils followed by FTIR simultaneously with CD and electron microscopy. Protein Sci. 9, 1960-1967.

39. Zurdo, J., Guijarro, J. I., Jiménez, J. L., Saibil, H. R. \& Dobson, C. M. (2001). Dependence on solution conditions of aggregation and amyloid formation by an SH3 domain. J. Mol. Biol. 311, 325-340.

40. Zurdo, J., Guijarro, J. I. \& Dobson, C. M. (2001). Preparation and characterization of purified amyloid fibrils. J. Am. Chem. Soc. 123, 8141-8142.

41. Polverino de Laureto, P., Frare, E., Battaglia, F., Mossuto, M. F., Uversky, V. N. \& Fontana, A. (2005). Protein dissection enhances the amyloidogenic properties of alpha-lactalbumin. FEBS J. 272, 2176-2188.

42. Lansbury, P. T., Jr, Costa, P. R., Griffiths, J. M., Simon, E. J., Auger, M., Halverson, K. J. et al. (1995). Structural model for the beta-amyloid fibril based on interstrand alignment of an antiparallel-sheet comprising a Cterminal peptide. Nature Struct. Biol. 2, 990-998.

43. Jaroniec, C. P., MacPhee, C. E., Bajaj, V. S., McMahon, M. T., Dobson, C. M. \& Griffin, R. G. (2004). Highresolution molecular structure of a peptide in an amyloid fibril determined by magic angle spinning NMR spectroscopy. Proc. Natl Acad. Sci. USA, 101, 711-716.

44. Ritter, C., Maddelein, M. L., Siemer, A. B., Luhrs, T. Ernst, M., Meier, B. H. et al. (2005). Correlation of structural elements and infectivity of the HET-s prion. Nature, 435, 844-848.

45. Kheterpal, I., Zhou, S., Cook, K. D. \& Wetzel, R. (2000) Abeta amyloid fibrils possess a core structure highly resistant to hydrogen exchange. Proc. Natl Acad. Sci. USA, 97, 13597-13601.

46. Kheterpal, I., Lashuel, H. A., Hartley, D. M., Walz, T., Lansbury, P. T., Jr \& Wetzel, R. (2003). Abeta protofibrils possess a stable core structure resistant to hydrogen exchange. Biochemistry, 42, 14092-14098.

47. Hoshino, M., Katou, H., Hagihara, Y., Hasegawa, K., Naiki, H. \& Goto, Y. (2002). Mapping the core of the beta(2)-microglobulin amyloid fibril by H/D exchange. Nature Struct. Biol. 9, 332-336.

48. Carulla, N., Caddy, G. L., Hall, D. R., Zurdo, J., Gairi, M., Feliz, M. et al. (2005). Molecular recycling within amyloid fibrils. Nature, 436, 554-558.

49. Kheterpal, I., Williams, A., Murphy, C., Bledsoe, B. \& Wetzel, R. (2001). Structural features of the Abeta amyloid fibril elucidated by limited proteolysis. Biochemistry, 40, 11757-11767.

50. Miake, H., Mizusawa, H., Iwatsubo, T. \& Hasegawa, M. (2002). Biochemical characterization of the core structure of alpha-synuclein filaments. J. Biol. Chem. 277, 19213-19219.
51. Baxa, U., Taylor, K. L., Wall, J. S., Simon, M. N., Cheng, N., Wickner, R. B. \& Steven, A. C. (2003). Architecture of Ure2p prion filaments: the N-terminal domains form a central core fiber. J. Biol. Chem. 278, 43717-43727.

52. Bousset, L., Briki, F., Doucet, J. \& Melki, R. (2003). The native-like conformation of Ure2p in fibrils assembled under physiologically relevant conditions switches to an amyloid-like conformation upon heat-treatment of the fibrils. J. Struct. Biol. 141, 132-142.

53. Polverino de Laureto, P., Taddei, N., Frare, E., Capanni, C., Costantini, S., Zurdo, J. et al. (2003). Protein aggregation and amyloid fibril formation by an $\mathrm{SH} 3$ domain probed by limited proteolysis. J. Mol. Biol. 334, 129-141.

54. Fontana, A., Polverino de Laureto, P., De Filippis, V., Scaramella, E. \& Zambonin, M. (1997). Probing the partly folded states of proteins by limited proteolysis. Fold. Des. 2, R17-R26.

55. Fontana, A., Polverino de Laureto, P., De Filippis, V., Scaramella, E. \& Zambonin, M. (1999). Limited proteolysis in the study of protein conformation. In Proteolytic Enzymes: Tools and Targets (Sterchi, E. E. \& Stöcker, W., eds), pp. 257-284, Springer Verlag, Heidelberg.

56. Hubbard, S. J. (1998). The structural aspects of limited proteolysis of native proteins. Biochim. Biophys. Acta, 1382, 191-206.

57. Fontana, A., Polverino de Laureto, P., Spolaore, B., Frare, E., Picotti, P. \& Zambonin, M. (2004). Probing protein structure by limited proteolysis. Acta Biochim. Pol. 51, 299-321.

58. Li, A., Sowder, R. C., Henderson, L. E., Moore, S. P., Garfinkel, D. J. \& Fisher, R. J. (2001). Chemical cleavage at aspartyl residues for protein identification. Anal. Chem. 15, 5395-5402.

59. Malisauskas, M., Zamotin, V., Jass, J., Noppe, W., Dobson, C. M. \& Morozova-Roche, L. A. (2003). Amyloid protofilaments from the calcium-binding protein equine lysozyme: formation of ring and linear structures depends on $\mathrm{pH}$ and metal ion concentration. J. Mol. Biol. 330, 879-890.

60. Polverino de Laureto, P., Frare, E., Gottardo, R., Van Dael, H. \& Fontana, A. (2002). Partly folded states of members of the lysozyme/lactalbumin superfamily: a comparative study by circular dichroism spectroscopy and limited proteolysis. Protein Sci. 11, 2932-2946.

61. Fruton, J. S. (1970). The specificity and mechanism of pepsin action. Advan. Enzymol. Relat. Areas Mol. Biol. 33, 401-443.

62. Fabian, H., Choo, L. P., Szendrei, G. I., Jackson, M., Halliday, W. C., Otvos, L., Jr \& Mantsch, H. H. (1993). Infrared spectroscopic characterization of Alzheimer plaques. Appl. Spectrosc. 47, 1513-1518.

63. Zandomeneghi, G., Krebs, M. R., McCammon, M. G. \& Fändrich, M. (2004). FTIR reveals structural differences between native beta-sheet proteins and amyloid fibrils. Protein Sci. 13, 3314-3321.

64. Krimm, S. \& Bandekar, J. (1986). Vibrational spectroscopy and conformation of peptides, polypeptides and proteins. Advan. Protein Chem. 38, 181-364.

65. Arrondo, J. L., Muga, A., Castresana, J. \& Goni, F. M. (1993). Quantitative studies of the structure of proteins in solution by Fourier-transform infrared spectroscopy. Prog. Biophys. Mol. Biol. 59, 23-56.

66. Barth, A. (2000). The infrared absorption of amino acid side chains. Prog. Biophys. Mol. Biol. 74, 141-173.

67. Haezebrouck, P., Joniau, M., Van Dael, H., Hooke, 
S. D., Woodruff, N. D. \& Dobson, C. M. (1995). An equilibrium partially folded state of human lysozyme at low pH. J. Mol. Biol. 246, 382-387.

68. Fink, A. L. (1998). Protein aggregation: Folding aggregates, inclusion bodies and amyloid. Fold. Des. 3, R9-R23.

69. Serpell, L. C. (2000). Alzheimer's amyloid fibrils: Structure and assembly. Biochim. Biophys. Acta, 1502, $16-30$.

70. Jiménez, J. L., Tennent, G., Pepys, M. \& Saibil, H. R. (2001). Structural diversity of ex vivo amyloid fibrils studied by cryo-electron microscopy. J. Mol. Biol. 311, 241-247.

71. von Bergen, M., Barghorn, S., Muller, S. A., Rickardt, M., Biernat, J., Mandelkow, E. M. et al. (2006). The core of tau-paired helical filaments studied by scanning transmission electron microscopy and limited proteolysis. Biochemistry, 45, 6446-6457.

72. Kajava, A. V., Baxa, U., Wickner, R. B. \& Steven, A. C. (2004). A model for Ure2p prion filaments and other amyloids: The parallel superplated $\beta$-structure. Proc. Natl Acad. Sci. USA, 101, 7885-7890.

73. Johnson, R. J., Christodoulou, J., Dumoulin, M., Caddy, G. L., Alcocer, M. J., Murtagh, G. J. et al. (2005). Rationalising lysozyme amyloidosis: Insights from the structure and solution dynamics of T70N lysozyme. J. Mol. Biol. 352, 823-836.

74. Dumoulin, M., Last, A. M., Desmyter, A., Decanniere, K., Canet, D., Larsson, G. et al. (2003). A camelid antibody fragment inhibits the formation of amyloid fibrils by human lysozyme. Nature, 14, 783-788.

75. Kelly, J. W. (1998). The alternative conformations of amyloidogenic proteins and their multi-step assembly pathways. Curr. Opin. Struct. Biol. 8, 101-106.

76. Dobson, C. M. (2003). Protein folding and diseases: A view from the first Horizon Symposium. Nature Rev. Drug Discov. 2, 154-160.

77. Uversky, V. N. \& Fink, A. L. (2004). Conformational constraints for amyloid fibrillation: The importance of being unfolded. Biochim. Biophys. Acta, 1698, 131-153.

78. Rochet, J. C. \& Lansbury, P. T., Jr (2000). Amyloid fibrillogenesis: Themes and variations. Curr. Opin. Struct. Biol. 10, 60-68.

79. Jahn, T. R. \& Radford, S. E. (2005). The Yin and Yang of protein folding. FEBS J. 272, 5962-5970.
80. Baldwin, A. J., Bader, R., Christodoulou, J., MacPhee, C. E., Dobson, C. M. \& Barker, P. D. (2006). Cytochrome display on amyloid fibrils. J. Am. Chem. Soc. 128, 2162-2163.

81. Dobson, C. M. (2005). Structural biology: Prying into prions. Nature, 435, 747-749.

82. López de la Paz, M. \& Serrano, L. (2004). Sequence determinants of amyloid fibril formation. Proc. Natl Acad. Sci. USA, 101, 87-92.

83. Pawar, A. P., Dubay, K. F., Zurdo, J., Chiti, F., Vendruscolo, M. \& Dobson, C. M. (2005). Prediction of "aggregation-prone" and "aggregation-susceptible" regions in proteins associated with neurodegenerative diseases. J. Mol. Biol. 350, 379-392.

84. Chiti, F. \& Dobson, C. M. (2006). Protein misfolding, functional amyloid, and human disease. Ann. Rev. Biochem. 75, 333-366.

85. Chung, E. W., Nettleton, E. J., Morgan, C. J., Gross, M., Miranker, A., Radford, S. E. et al. (1997). Hydrogen exchange properties of proteins in native and denatured states monitored by mass spectrometry and NMR. Protein Sci. 6, 1316-1324.

86. Canfield, R. E., Kamerman, S., Sobel, H. H. \& Morgan, F. J. (1971). Primary structure of lysozymes from man and goose. Nature New Biol. 232, 16-17.

87. Gill, S. G. \& von Hippel, P. H. (1989). Calculation of protein extinction coefficients from amino acid sequence data. Anal. Biochem. 182, 319-326.

88. Byler, D. M. \& Susi, H. (1986). Examination of the secondary structure of proteins by deconvolved FTIR spectra. Biopolymers, 25, 469-487.

89. Arrondo, J. L., Castresana, J., Valpuesta, J. M. \& Goni, F. M. (1994). Structure and thermal denaturation of crystalline and noncrystalline cytochrome oxidase as studied by infrared spectroscopy. Biochemistry, 33, 11650-11655.

90. García-García, J., Corbalan-Garcia, S. \& GomezFernandez, J. C. (1999). Effect of calcium and phosphatidic acid binding on the C2 domain of PKC alpha as studied by Fourier transform infrared spectroscopy. Biochemistry, 38, 9667-9675.

91. Blake, C. C., Pulford, W. C. \& Artymiuk, P. J. (1983). Xray studies of water in crystals of lysozyme. J. Mol. Biol. 167, 693-723.

Edited by C. R. Matthews

(Received 28 April 2006; received in revised form 20 June 2006; accepted 21 June 2006) Available online 7 July 2006 